\title{
LA BIBLIOFILIA DE JULIÁN RIBERA
}

Maribel FIERRO

C.S.I.C. Madrid

Sabido es que los arabistas F. Codera y su discípulo J. Ribera viéronse obligados por las carencias de la época a dominar la técnica de la tipografía árabe, constituyendo la Bibliotheca Arabico-Hispana $(B A H)$ uno de los frutos de ese empeño. Pero además Ribera aplicó a esa técnica el genio de su inventiva, tal y como recordaba M. Asín Palacios en 1928:

Como típógrafo ... no sólo organizó ... la imprenta árabe de Codera sobre bases más normales y económicas, sino que, años después, concibió y realizó el genial proyecto de reformar la complicada y numerosa caja de la tipografía árabe, que consta de 200 tipos, reduciéndola al inverosímil número de 24 punzones, que representa una economía superior a la de todas las tipografías europeas, así en el tiempo y atención que la composición exige del cajista, como en la corrección de pruebas y distribución de los tipos, y, sobre todo, en el papel, capaz de contener doble número de líneas. Este nuevo sistema tipográfico, verdadera revolución en el arte de la imprenta árabe, fue llevado a la práctica en el año 1909 por la casa Gans, de Madrid, sobre dibujos debidos al ingeniero y arabista Prieto Vives, colaborador de Ribera; $y$, desde esa fecha, todos los textos árabes que en España han visto la luz pública han sido impresos ya con esa caja, propiedad de la escuela. El invento, que de tal debe ser calificado, no pasó, huelga decirlo, las fronteras ... Para industrializarlo, hacen falta capitales que a los arabistas no sobran ${ }^{1}$.

${ }^{1}$ Introducción de M. Asin Palacios a las Disertaciones y opúsculos de J. Ribera (2 vols., Madrid, 1928), p. CXIII. Su actividad tipográfica es también recordada por E. García Gómez, "Don Julián Ribera y Tarragó", Al-Andalus II (1934), pp. I-VII. 
J. Ribera alcanzó también gran destreza como litógrafo, logrando imitar a la perfección la escritura árabe magrebŕ. Su destreza dio lugar a una sabrosa anécdota, rememorada por $\mathrm{Asin}^{2}$. En su afán por conseguir obras árabes que versasen sobre la historia de al-Andalus, redactó Ribera un catálogo de esas obras (basándose en los datos suministrados por la $B A H$ ), "cuyos títulos y autores litografió contrahaciendo maravillosamente el tipo de letra árabe magrebí". Ese catálogo circuló entre los libreros norteafricanos, sin que diese los frutos apetecidos, aunque si otro insospechado. Habiendo ido a parar un ejemplar al "Seminar für Orientalische Sprachen" de Berlín, G. Kampffmeyer se volcó en su estudio, produciendo en 1906 un erudito artículo en el que daba sobre cada uno de los libros mencionados "cuantas noticias, referentes a su autor y materia, encontró sin gran esfuerzo en la rica Bibliotheca Arabico-Hispana, de cuyas páginas cabalmente había extraído Ribera el catálogo"3.

Tipógrafo, litógrafo y asimismo fotografo: "Gracias a su habilidad en este arte (la fotografía - mío), Ribera pudo proporcionarse para sí y para sus discípulos copias de manuscritos árabes, preciosos y exóticos, cuyas noticias tantos puntos oscuros de nuestra historia dilucidan"4.

Cuando en 1887 Ribera obtiene la Cátedra de Lengua Árabe de la Universidad de Zaragoza, se encuentra sin apenas materiales de trabajo y utiliza su propio dinero para comprar los libros indispensables. Es en esa época cuando empieza a trabajar en el fondo de manuscritos árabes y aljamiados que habían sido descubiertos en 1884 en Almonacid de la Sierra. A partir de ellos, publica una Colección de textos aljamiados (Zaragoza, 1888), que será texto de iniciación para sus estudiantes, "preservando así de la ruina a muchos otros manuscritos aljamiados que se habrian perdido, como tantos se perdieron anteriormente, por la ignorancia de su escritura"5. En 1910, Ribera logra que la "Junta para

${ }^{2}$ Introd. cit., p. XXVII.

${ }^{3}$ Más tarde, G. Kampffmeyer rectificó su error: v. F. Rosenthal, $A$ history of Muslim historiography (Leiden, 1968), p. 4, nota 1.

${ }^{4}$ M. Asín Palacios, introd. cit., p. CXIII.

${ }^{5}$ Ibid., p. XXVII. Sobre el nacimiento del interés por la literatura aljamiada, v. M. Manzanares de Cirre, Arabistas españoles del siglo XIX (Madrid, 1972), 
Ampliación de Estudios" compre la colección de manuscritos árabes y aljamiados perteneciente a $\mathrm{D}$. Pablo Gil y procedente del descubrimiento de Almonacid. La colección pasó a la sección árabe del Centro de Estudios Históricos de dicha Junta, más tarde a la Escuela de Estudios Árabes de Madrid, que en 1939 entró a formar parte del C.S.I.C., en cuyo Departamento de Estudios Árabes del Instituto de Filología de Madrid se encuentra actualmente ${ }^{6}$. El catálogo de esta colección puede consultarse en el volumen titulado Manuscritos árabes y aljamiados de la Biblioteca de la Junta. Noticia y extractos por los alumnos de la sección árabe bajo la dirección de J. Ribera y M. Asin, Madrid: Junta para la Ampliación de Estudios e Investigaciones Científicas. Centro de Estudios Históricos, 1912. Gracias, pues, a los desvelos de Ribera, esta colección no sólo fue adquirida por el Estado para el uso de los investigadores, sino que se puso a disposición de éstos un cuidado catálogo ${ }^{7}$. En él se reproducen páginas de los manuscritos y documentos considerados de interés por su valor paleográfico, advirtiendo Ribera y Asín: "Se ha procurado que hubiese variedad de fechas y procedencias. La paleografía árabe española es asunto que aún está por estudiar a fondo y conviene ir reuniendo selectos materiales" ${ }^{18}$. El comentario

pp. 76-9, así como J. T. Monroe, Islam and the Arabs in Spanish Scholarship (Leiden, 1970), pp. 71-2. El impulso dado en el siglo XIX a este campo de investigación ha tenido continuidad a lo largo del presente siglo con numerosos trabajos que sería muy largo reseñar y que además cuentan con su propio boletín bibliográfico (Aljamía). Baste con recordar la existencia de una "Colección de literatura española aljamiado-morisca - CLEAM", dirigida por A. Galmés de Fuentes.

${ }^{6}$ En 1988 se inició la restauración de los manuscritos de esta colección a cargo del "Instituto de Conservación y Restauración de Bienes Culturales" del Ministerio de Cultura. Por el momento se han restaurado los mss. $n^{\text {os }} 9,19,29$, 51. Su estudio paleográfico ha sido iniciado por A. Labarta y C. Barceló.

${ }^{7}$ Sería de desear la actualización de ese catálogo, es decir, una nueva versión en la que se corrigiesen los errores advertidos y se añadiesen todos los nuevos datos que sobre la colección se han ido acumulando desde que el catálogo fue publicado.

${ }^{8}$ Ob. cit., p. XXIX. Ya F. Codera habia puesto de relieve la importancia de estos estudios en su artículo "Paleografia árabe. Dificultades que ofrece. Su estado. Medios de desarrollo", B.R.A.H. XXXIV (1899). Este artículo es citado en la revista Nouvelles des Manuscrits du Moyen-Orient I/2 (1993) como 
final, hoy en día, sigue siendo vigente, aunque en los últimos años ha habido mucha actividad en el campo de los estudios codicológicos y paleográficos?.

En la carta de J. Ribera a R. Basset que acompaña este artículo se evidencia el interés por la correcta lectura de las cifras árabes que sentían Ribera y su maestro F. Codera. Al describir el ms. n LVI de la Colección Gayangos, explica Ribera: "Según la nota final se concluyó de copiar en el mes de Dulhicha del año $\$ 06$ que según interpretación de D. Francisco Codera que ha estudiado las distintas formas de numeración usadas por los occidentales puede leerse 976 (antes leía 876 , pero ahora tiene seguridad del 900)" ${ }^{10}$.

Un año después de incorporarse a la cátedra de Zaragoza, en 1888, visitaba Ribera el Archivo de la Corona de Aragón en Barcelona "y preguntaba si en aquel interesante Centro de la Historia medieval se guardaba algún documento árabe. Mostráronle los archiveros un arcón, en el que había algunas docenas de pergaminos escritos en esta lengua, e inmediatamente dedicóse a la tarea inicial de exploración y catalogación de tales diplomas. Éste fue, pues, la primera tentativa de estudio sobre dicho fondo"11. El catálogo por él elaborado permaneció inédito, siendo completado por sus discípulos Ramón García de Linares y Maximiliano Alarcón, poniendo así a disposición de los especialistas un rico material para la historia de las relaciones internacionales del reino de Aragón con los reinos musulmanes ${ }^{12}$.

precursor del FiMMOD (Fichier des Manuscrits Moyen-Orientaux Datés) en el que se pretende recoger la información referente a todos los manuscritos en escritura árabe fechados por un colofón legible y anteriores al año 1500 d.C.

${ }^{9}$ En 1992 tuvo lugar en Rabat el "Colloque Internationale 'Le Manuscrit arabe et la codicologie"". Por su parte, "al-Furqān Islamic Heritage Foundation" organizó una conferencia sobre "Codicology of Islamic Manuscripts" en diciembre de 1993.

${ }^{10}$ En este terreno contamos ahora con el estudio de A. Labarta y C Barceló, Números y cifras en los documentos arabigohispanos (Córdoba, 1988).

${ }^{11}$ M. Alarcón y R. García de Linares, Los documentos árabes diplomáticos del Archivo de la Corona de Aragón (Madrid/Granada, 1940), p. VII. V. también M. Asín, introd. cit., pp. XXV-XXVI.

${ }^{12}$ En este terreno, en el de los documentos árabes diplomáticos que se conservan en los archivos peninsulares, no se ha dejado de trabajar. Baste como 
El interés de Ribera por los manuscritos y documentos árabes no se limitó a los fondos peninsulares. Ya he mencionado antes el recurso que imaginó para ponerse en contacto con los bibliófilos norteafricanos que pudieran poseer manuscritos de obras andalusíes. Por la misma época, E. Saavedra y Moragas intentaba que los arabistas españoles estableciesen contactos culturales con los países islámicos ${ }^{13}$. Con este fin, puso en juego su influencia para que Ribera viajase a Marruecos en 1893 como miembro de la embajada del general Martínez Campos con la misión de comprar el mayor número posible de libros. "Su estancia en Marraquex, durante todo el invierno que aquellas negociaciones diplomáticas consumieron, aprơvechóla Ribera para estudiar de cerca la vida y la psicología marroquí, al margen de sus búsquedas, poco fructíferas, de manuscritos interesantes a nuestras bibliotecas" ${ }^{14}$. Fue ésta una preocupación que compartía con su maestro Codera ${ }^{15}$ y que ha sido y es una constante entre los arabistas españoles ${ }^{16}$.

Hoy en día pocos son los manuscritos de interés para la historia de al-Andalus que no hayan sido editados, ya sea en España ya en los países árabes e islámicos. Ribera fue un gran impulsor de esta labor de edición. Entre 1882 y 1885 prepara junto con Codera la edición de los

ejemplo los numerosos artículos sobre documentos del Archivo Histórico Nacional publicados por M. Arribas Palau.

13 V. Monroe, ob, cit., p. 104.

${ }^{14}$ M. Asín, introd. cit., p. LV.

${ }^{15} \mathrm{~V}$. los numerosos artículos publicados por Codera acerca de fondos de manuscritos interesantes para la historia de al-Andalus, de los que se puede encontrar una relación en Homenaje a D. Francisco Codera en su jubilación del profesorado. Estudios de erudición oriental, con una introducción de D. Eduardo Saavedra (Zaragoza, 1904), pp. XXXIV-XXXVI.

${ }^{16}$ Actualmente, $M^{a}$ L. Ávila y L. Molina dirigen un proyecto con miras a crear un fondo de reproducciones de manuscritos árabes relativos a al-Andalus en soporte electrónico, que permitirá la consulta de los textos originales de las obras incluidas en el archivo de una manera rápida y cómoda, sin riesgo de que el documento o su copia fotográfica o reprográfica sufran el menor deterioro por un uso repetido, con la posibilidad de consulta simultánea de un mismo documento por varios usuarios, de modificar parámetros como color, brillo, luminosidad, resolución, para mejorar la legibilidad del documento, de obtener una copia impresa en caso necesario, e incluso de acceder al archivo remotamente desde cualquier ordenador que pueda conectarse con el sistema principal. 
tres primeros tomos de la $B A H$, cuyos últimos tomos se imprimen en Zaragoza entre 1893 y 1895, utilizando la nueva tipografía por él inventada ${ }^{17}$. De esta manera veían la luz los textos biobibliográficos básicos para acometer no sólo el estudio de la actividad intelectual de al-Andalus, sino también de muy diferentes aspectos de su trayectoria histórica y social ${ }^{18}$. Son textos todos ellos que aún hoy en día están siendo explotados y analizados, al margen de ser obras de consulta y referencia indispensables. Pero Ribera no se limitó a colaborar en esta empresa.

Editar textos árabes simplemente, sin traducciones, análisis o resúmenes que los hagan asequibles a los no iniciados, fué siempre en España empresa expuesta a las burletas y donaires satíricos del vulgo ignaro, que no acierta a comprender que tales ediciones previas puedan ser tan indispensables para las futuras monografías de síntesis histórica, como las preparaciones microscópicas lo son para los estudios de histología o biología. Digamos entre paréntesis que para este prejuicio son vulgo no pocos eruditos y hombres de ciencia. Ribera, pues, haciéndose cargo de tales resistencias de ambiente, planeó la publicación de una Colección de Estudios Árabes, órgano adecuado para aquellos fines: había de constar de pequeños volúmenes en 8 , en los que se vulgarizasen, sin excesivo aparato erudito, los resultados de las investigaciones realizadas por la escuela en varios sectores de la historia política y cultural del islam, singularmente español ${ }^{19}$.

${ }^{17}$ V. al respecto M. Asín, introd, cit., pp. XXIV y XXVIII-XXIX. Sobre las dificultades de financiación de esta empresa, v. Monroe, ob. cit., pp. 132-3. En febrero de 1883, F. Codera comunica a Dozy que van a tirar 600 ejemplares de cada volumen de la $B A H$, de los cuales 200 serán comprados por el gobierno español, preguntándose Codera si los 400 restantes podrían tener salida fuera de España. V. al respecto M. Fierro, "Algunas cartas de arabistas españoles a R. Dozy y M. J. de Goeje", Miscelánea de Estudios Árabes y Hebraicos XL-XLI (1991-1992), p. 122.

${ }^{18} \mathrm{~V}$. a modo de ejemplo de la riqueza de datos que contienen esas obras los cinco volúmenes aparecidos hasta el momento de los Estudios onomásticobiográficos de al-Andalus (Madrid/Granada, 1988-1992). Otro ejemplo es el artículo de M. de Epalza, "La caiguda de València i altres caigudes d'Al-Andalus, segons l'obra en prosa d'Ibn al-Abbär", Ibn al-Abbär. Polític i escriptor àrab valencià (1199-1260). Actes del Congrés Internacional "Ibn al-Abbär $i$ el seu temps". Onda, 20-22 febrer, 1989, Valencia, 1990, pp. 19-42.

19 M. Asín, introd. cit., pp. XXIX-XXX. En las últimas décadas, la 
En ese terreno de la historia cultural Ribera compuso dos estudios pioneros en su día que iluminan la historia del libro en al-Andalus: "La enseñanza entre los musulmanes españoles"20 y "Bibliófilos y bibliotecas en la España musulmana"21. En el primero se detiene a analizar, entre otros aspectos, la organización "de las varias disciplinas de la enseñanza superior (cuyo examen particularizado equivale a una historia de la bibliografía y literatura teológica, jurídica, filológica, filosófica y científica de los árabes españoles)" ${ }^{22}$. En el segundo, traza un apasionante cuadro de la difusión de los libros entre los andalusíes, difusión que achaca, entre otras razones, al temprano uso del papel y a las características de la escritura árabe.

$\mathrm{El}$ amor por los libros se da por supuesto en todo investigador dedicado a las ciencias humanas y sociales. He querido recordar brevemente la amplitud y rasgos singulares que ese amor tuvo en el caso del insigne arabista e investigador "Sarqi" J. Ribera. Reproduzco a continuación una carta en la que asoma de nuevo su "bibliofilia". Se conserva dentro del fondo $\mathrm{R}$. Basset de la biblioteca de la Universidad de Leiden y está dirigida al arabista francés por J. Ribera ${ }^{23}$.

publicación de textos árabes en España ha sido posible gracias sobre todo a la labor del antiguo "Instituto Hispano-Árabe de Cultura", ahora "Instituto de Cooperación con el Mundo Árabe". Este organismo ha cofinanciado junto con el Consejo Superior de Investigaciones Científicas la colección Fuentes ArábigoHispanas, que cuenta en la actualidad con quince volúmenes en los que se han puesto a disposición de los investigadores ediciones y/o traducciones de textos andalusies.

${ }^{20}$ Discurso leído en la Universidad de Zaragoza (Zaragoza, 1893); reeditado en Disertaciones y opúsculos, I, 229-359. Ribera prestó también atención al sistema de enseñanza en el Islam oriental: v. su "Origen del Colegio nidamí de Bagdad", ob, cit., I, 361-383.

21 Disertaciones y opúsculos, I, 181-227; v. Monroe, ob. cit., pp. 158-9.

${ }^{22}$ M. Asín, introd. cit., p. XXXIV. V. también Monroe, ob. cit., pp. 157-8.

23 Tiene la signatura Or. 14055 A 11: v. J. J. Witkam, Catalogue of Arabic Manuscripts in the Library of the University of Leiden and other collections in the Netherlands, Leiden, 1983, fasc. 1, p. 101. Quiero agradecer al personal de dicha biblioteca, y en especial al Dr. Witkam, la ayuda prestada durante mi estancia en Leiden en el verano de 1988. 
Universidad de Zaragoza

Facultad de Filosofía y Letras

Particular

Sr. D. Renato Basset.

Muy Sr. mío y estimado colega: de vuelta de mi escursión (sic) a Madrid, à donde fui para dar unas lecturas en la Escuela de Estudios Superiores del Ateneo, puedo escribirle á V. para darle noticia del Ben Alcardabús.

La Academia de la Historia posee no uno sino tres manuscritos de la obra

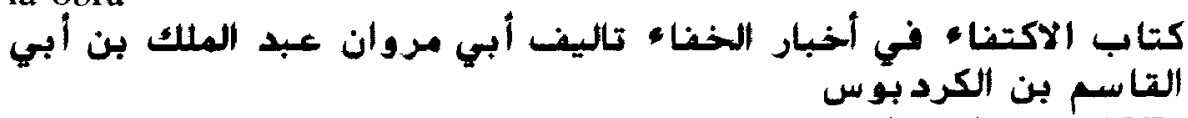

Dos de ellos son de la Colección Gayangos, à saber el num. LVI

Dimensiones de la caja escrita (tiene 25 líneas).

$2,10 \times 14,5$

Dimensiones del papel

$26,2 \times 20,0$

Tiene 147 hojas útiles; carácter occidental antiguo (magrebí). Está algo apolillado.

Bastante correcto.

Según la nota final se concluyó de copiar en el mes de Dulhicha del año $\varphi 06$ que según interpretación de D. Francisco Codera que ha estudiado las distintas formas de numeración usadas por los occidentales puede leerse 976 (antes leía él 876; pero ahora tiene seguridad del 900).

Este códice lo extractó Gayangos y publicó algo Dozy.

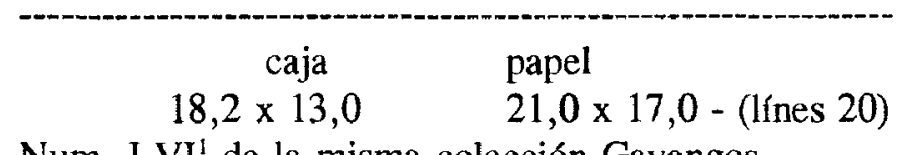

Num. LVI ${ }^{1}$ de la misma colección Gayangos.

Ms. en folio de 223 hojas útiles, carácter de la letra magrebi (occidental) antiguo. Está restaurado; habiendosele añadido por el principio 4 hojas de letra moderna y 8 hojas por el fin. 
Tinta corrosiva (sulfato de hierro); por lo cual faltan algunas palabras. No sabemos la fecha del ms. porque es de letra moderna el fin.

Aunque no es muy incorrecto, es más correcto el primero que éste.

Ms. num. 94 de los Ms. de la Real Academia - adquirido en Túnez.

Lleva título y nombre de autor diferente falsificado; pero el texto corresponde á la obra de Ben Alcardabús.

De este ms. dió cuenta D. Fran ${ }^{c o}$. Codera en el Boletín de la Academia tomo 21 pag. 29.

Es menos correcto que los dos anteriores y de letra y papel modernos.

Me convencí de que era Ben Alcardabús por el cotejo que hicimos en varias partes del ms.

Dentro de 15 o 20 días terminaré la impresión de las conferencias mías que he dado en Madrid y tendré el gusto de mandarle un ejemplar. Entretanto queda siempre suyo afmo. s.s.q.b.s.m.

Julián Ribera

Zaragoza 13 Dcmbre 1897 


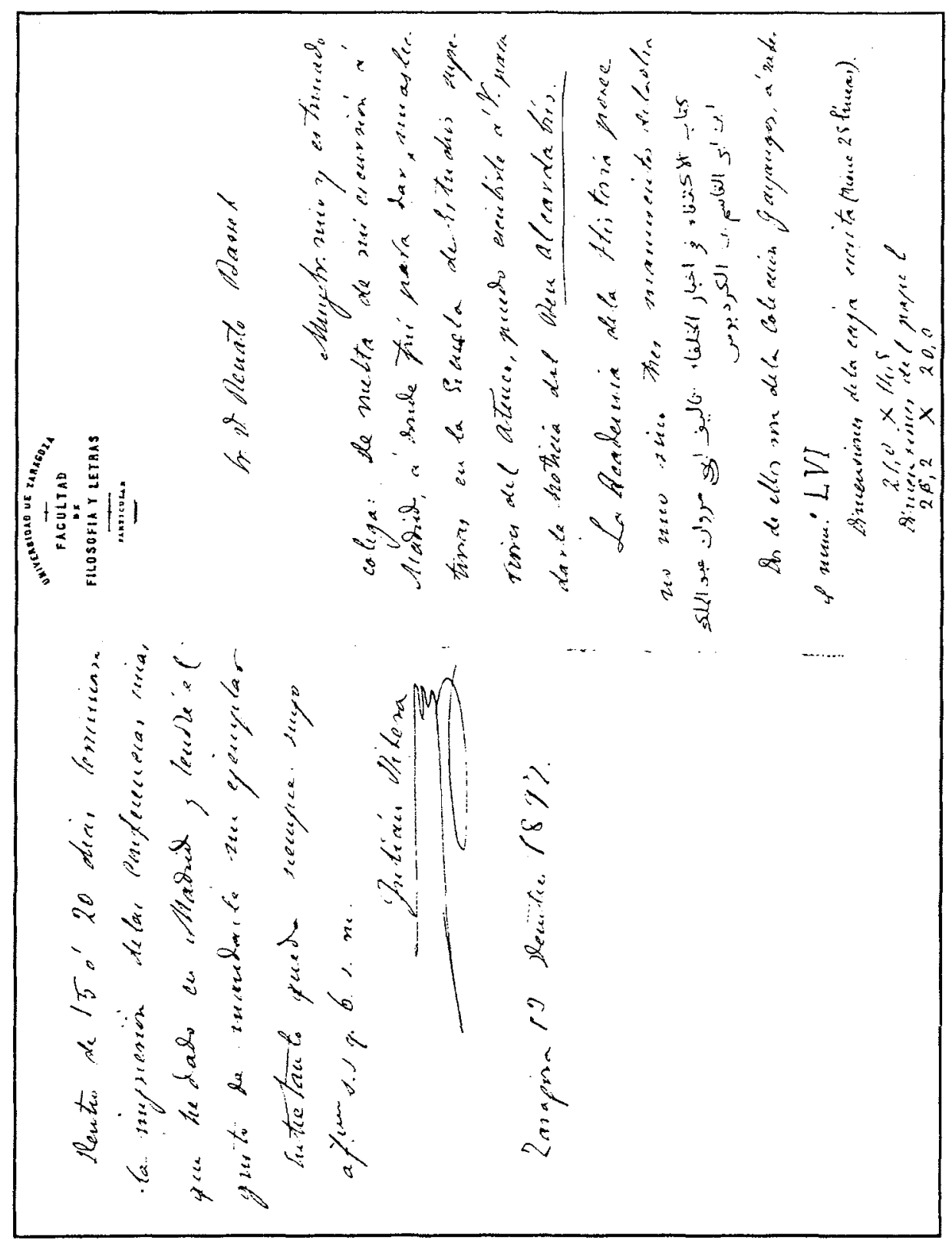




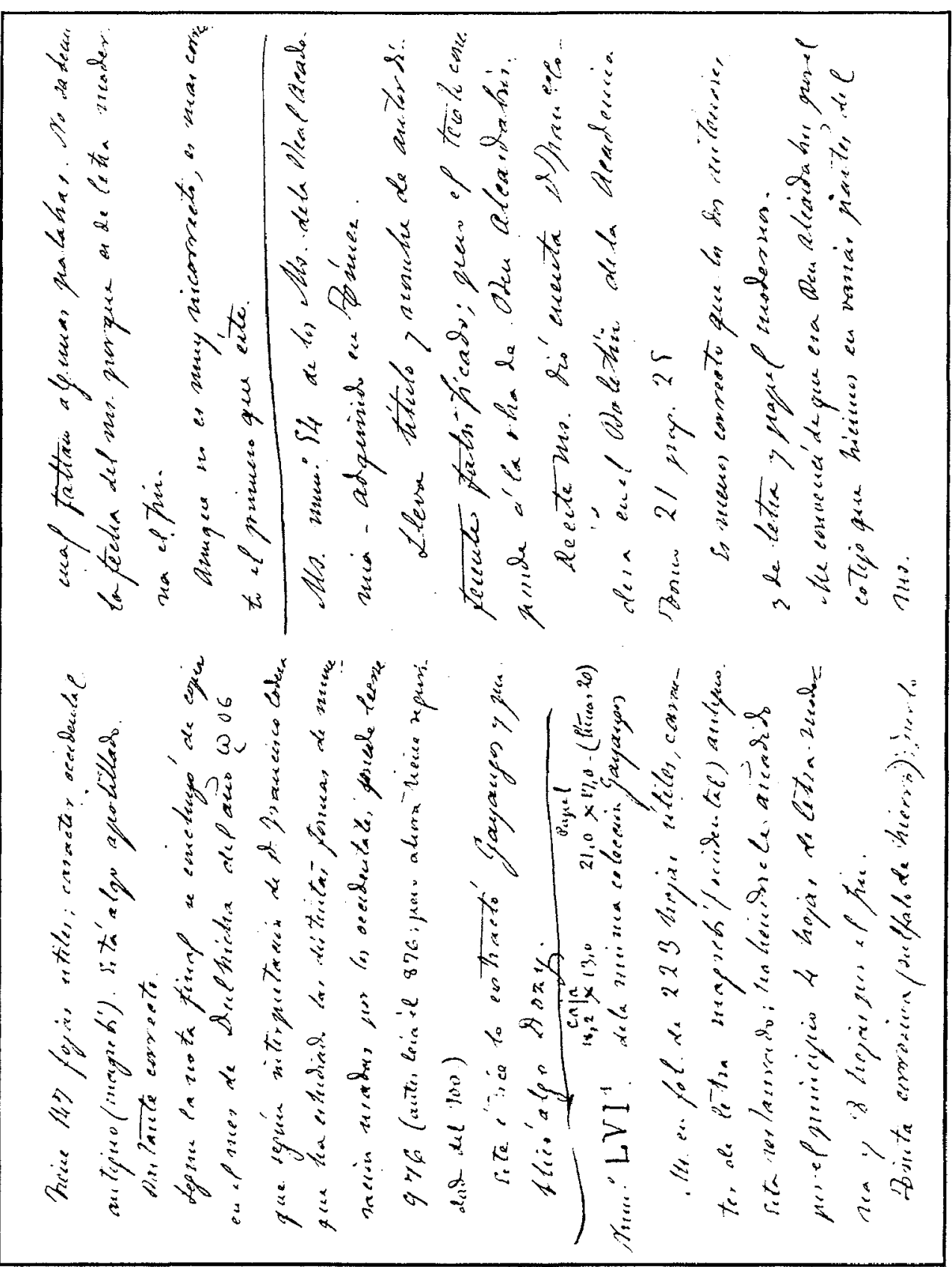

